\title{
Post Implementation Evaluation of Lahore - Sheikhupura - Faisalabad Dual Carriageway - A Built Operate Transfer (BOT) Project
}

\author{
Anwaar Ahmed ${ }^{1}$, Sandeerah Choudhary ${ }^{2}$, Muhammad Irfan ${ }^{3}$ \\ ${ }^{1}$ National Institute of Transportation, National University of Sciences and Technology, Risalpur, Pakistan \\ ${ }^{2}$ Civil Engineering Department, Commission on Science and Technology for Sustainable Development in the South (COMSATS) University, \\ Wah Campus, Wah Cantonment, Pakistan \\ ${ }^{3}$ National Institute of Transportation, National University of Sciences and Technology, Risalpur, Pakistan
}

Email addresses:

anwaar5148@gmail.com(A.Ahmed),dranwaar@scee.nust.edu.pk(A.Ahmed),sandeerah.choudhary@ciitwah.edu.pk(S.Choudhary), mirfan@mce.nust.edu.pk(M. Irfan)

\section{To cite this article:}

Anwaar Ahmed, Sandeerah Choudhary, Muhammad Irfan. Post Implementation Evaluation of Lahore - Sheikhupura - Faisalabad Dual Carriageway - A Built Operate Transfer (BOT) Project. International Journal of Transportation Engineering and Technology.

Vol. 4, No. 3, 2018, pp. 59-64. doi: 10.11648/j.ijtet.20180403.12

Received: August 9, 2018; Accepted: January 2, 2019; Published: January 5, 2019

\begin{abstract}
The transportation systems generally constitute the largest public-sector investment by any society. Despite of funding limitations, highway agencies continue striving to develop road network to meet needs of the society. In order to ensure optimal utilization of public money, there is a dire need of best project evaluation practices and monitoring of the expected impacts of highway investment decisions. Present study focused on post implementation evaluation of Lahore-Sheikhupura-Faisalabad Dual Carriageway, a 4-lane divided highway 115 Kilometer long that was constructed in 2006 through Build-Operate-Transfer (BOT) financing with a concession period of 22 years. For post-implementation evaluation five performance criteria were considered: safety, vehicle operating cost, fuel cost, lifecycle agency maintenance and operations cost, and lifecycle toll collection. Post-implementation evaluation was carried out using highway maintenance and rehabilitation strategies proposed by facility operator (concessioner). Present worth (2007 constant US\$) of travel time, safety and fuel saving was found to be \$US 429.290, -1.790, 65.080 Million respectively. Using facility operator's maintenance and rehabilitation strategy total maintenance and operations cost was found to be \$US 234.442 Million (2007 constant US\$). Also, present worth of toll collection was estimated as \$US 131.410 Million (2007 constant US\$). Positive net present value revealed that project is economically viable for society. Also, methodology used in present study can be used by highway agencies for carrying out post-construction evaluation of their projects.
\end{abstract}

Keywords: Post-Implementation Evaluation, BOT Project, Pakistan, Economic Efficiency

\section{Introduction}

The transportation systems generally constitute the largest public-sector investment by any society. Quality and quantity of transportation infrastructure has direct influence on the global competitiveness and economic vitality of a nation [1]. Transportation engineers and planners, policymakers, environmental groups, and the general public are interested in refined procedures of project evaluation. Thus there is a need of best project evaluation practices and monitoring of the expected impacts of alternative investment decisions and other stimuli on the operations of existing or planned transportation systems [2]. Post implementation evaluation of transportation project helps to judge the effectiveness of the project after it has been in public use for some time. Post implementation evaluation can help in quantifying the cost and benefits of the transportation system over its lifecycle and can serve as an important guideline for future investment decisions.

Pakistan is a developing country where road 
infrastructure is the main mean of transportation. Every year hundreds of billion are invested on road infrastructure. State of the road network is comparable with other countries of the region, but still, there is a room for improvement in terms of upgradation of existing infrastructure and construction of new arteries. In the last 20 years, there has been a considerable pressure on the development of road infrastructure and road network has proved itself to be the backbone of the transportation system in Pakistan. Despite of funding limitations, National Highway Authority of Pakistan continues to strive to develop road network to meet needs of the society through innovative funding options. In order to ensure optimal utilization of public money, there is a dire need of best project evaluation practices and monitoring of the expected impacts of highway investment decisions. A post implementation evaluation framework can be developed to check if the invested money in a particular project has really benefitted the society as a whole or not. Also, in context of developing countries like Pakistan, post-implementation evaluation is important as it will enable highway agency to identify procedural issues and help in implementation of improved procedures in future projects. In recent years many projects in Pakistan have been financed through BOT (Build-Operate-Transfer) model. In recent research effort post-implementation evaluation of Lahore - Sheikhupura - Faisalabad Dual Carriageway has been carried out. Lahore and Faisalabad Construction Company (LAFCO) Private Limited a subsidiary of Frontier Works Organization (FWO) was awarded contract of this highway for a 25-years (30 Sep 2003 - 29 Sep 2028) concession period under BOT financing model by Communication and Works Department $(\mathrm{C} \& \mathrm{~W})$ of Government of Punjab. LAFCO upgraded facilty from 2-lane highway to 4-lane divided facility, with partial access control. Lahore-Sheikhupura-Faisalabad Dual Carriageway, a 115 Kilometers long highway with five toll plazas for toll collection is in operation since January 2007.

Several studies on pre- and post-implementation evaluation have been carried out and several principles and procedures have been established for the calculations of travel time, safety, vehicle operating costs and environmental impacts of a road improvement project. Similarly different performance measures have been used in past studies for post-implementation evaluation. Post implementation evaluation of a project reviews project benefits such as improved safety and journey time, travel reliability and increased capacity of the system to meet the traffic demand [3]. Recent studies [2], [4] have provided a detailed list of performance measures based on overall highway agency goals and include safety, transportation system preservation, sustainability and environmental quality, cost effectiveness, reliability, mobility and accessibility as the key performance measures for post-implementation evaluation. Present research effort used general procedures outlined in [2] for post-implementation evaluation of a highway project. The research objectives set out for present study are:

1. To develop a generalized framework for post-implementation evaluation of a highway project

2. To demonstrate the applicability of developed framework using a case study

\section{Methodology}

Generalized framework used for post-implementation evaluation is shown in Figure 1. The detailed steps of study methodology are discussed in the ensuing paragraphs.

\subsection{Literature Review}

Detailed literature review of the post implementation methodologies and their associated factors like travel time and safety saving, fuel and economic efficiency was carried out in first step and procedures were selected to be used in post-implementation evaluation.

\subsection{Estimation of Travel Time Savings}

Travel time saving can be defined as time that can be saved if certain intervention is applied to a highway infrastructure and resulting saved time can be invested by the road user to make money, goods or services. Procedure of HCM are used to estimate travel time on rural arterial before intervention and in this method speed is expressed as function of peak direction volume to capacity ratio, signal density, flow rate, free flow speed and highway class [5]. COMSIS Corporation's method is used for the calculation of travel time savings after intervention as facility was upgraded to a divided highway [6]. Actual posted speed on highway before and after intervention was used to estimate free flow speed for estimation of travel time on facility before and after intervention. Facility had a posted speed of 75 Kilometers per hour (KMPH) for light vehicles and $65 \mathrm{KMPH}$ for heavy vehicles before intervention. After intervention facility is operating at 100 $\mathrm{KMPH}$ for light vehicles and $90 \mathrm{KMPH}$ for heavy vehicles, respectively.

Using facility travel time before and after intervention, travel time saving is estimated as follows:

$$
\text { Travel Time Savings (minutes) per traveler }=\text { TTBI }- \text { TTAI }
$$

Where TTBI and TTAI are the facility travel times before and after intervention, respectively

Using appropriate occupancy and appropriate unit travel time value, annual travel time saving is estimated as follows:

Travel Time Savings (Millions Rs) =AADT*Occupancy*Unit value of Travel time*Travel time saving per traveler (2) 


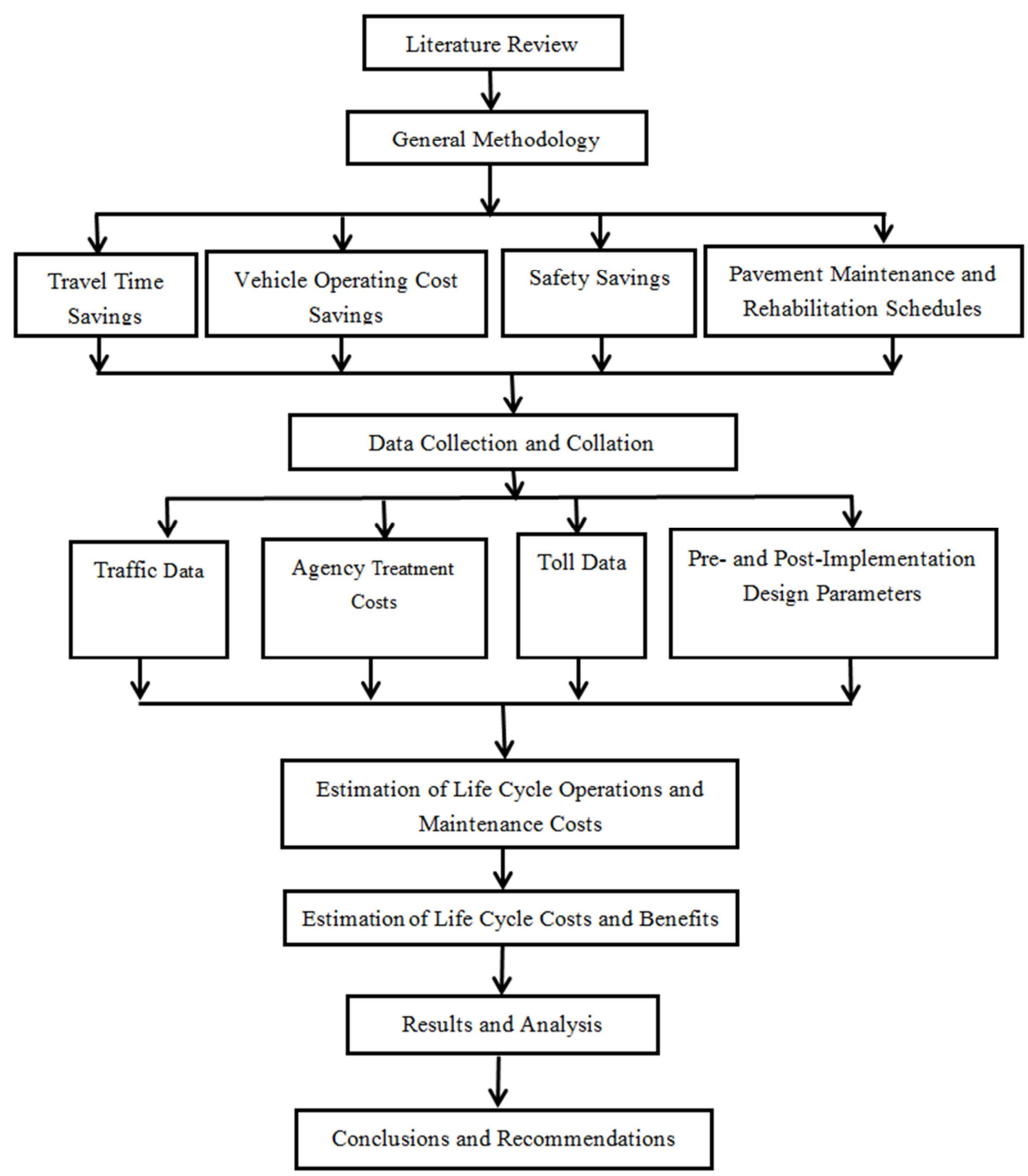

Figure 1. Generalize Study Methodology.

\subsection{Safety Saving}

The economic cost of traffic crashes is born by entire society (individuals, private firms and government) and is quantified in terms of loss/ damage of life and property and loss of productivity [2]. Whenever there is a transportation intervention, there is an associated safety component or direct/ indirect change in crash frequency and/or severity. Transportation experts are keen to quantify benefits of transportation intervention that reduces the rate or severity of accidents.

Lahore-Sheikhupura-Faisalabad Dual Carriageway had old design with inferior geometrics. Upgradation of highway to 4-lane divided facility resulted in improved geometrics, traffic signage and marking. Following procedures outlined in Sinha and Labi [2], safety benefits resulting from facility upgradation are estimated. Since crash rates for different highway functional classes are used from [7] therefore firstly annual million vehicle miles travelled were estimated. In second step fatal and non-fatal crashes per million vehicle kilometer travelled were estimated using traffic and crash data provided by LAFCO. Knowing the crash rate and unit crash cost, the vital inputs for our estimation [8] net cost of fatal and non-fatal crashes was estimated. Finally safety saving was estimated as follows:

$$
\text { Safety Saving }=\text { Cost of crashes before intervention }- \text { Cost of crashes after intervention }
$$

Since safety saving depends upon traffic volume, therefore with anticipated increase in traffic volume, these benefits may diminish in later years.

\subsection{Fuel Saving}

Vehicle operating costs (VOCs) is a variable cost that varies with vehicle use and is usually expressed in cents per kilometer/mile of travel by a particular vehicle [2]. Typically for highway transportation mode VOC involves cost of fuel, repair and maintenance of vehicle including tire use and usage based depreciation. Since fixed vehicle costs such as insurance cost, parking and time-dependent depreciation remain unaffected by highway improvement projects and thus are not considered in analysis [2]. Upgradation of a highway facility results in reduction of vehicle delays on 
nodes and links. Past studies [2] and [9] recommend that in evaluating the benefits of highway upgradation projects, VOC can be considered in terms of reduction in travel delays.
For quantifying the impact of travel delay on fuel cost using AASHTO (2003) methodology, delay time with and without the intervention is calculated as follows:

Change in delay $=$ Delay without intervention-Delay with intervention

Knowing the change in delay, unit fuel price and fuel consumption rate for different vehicle classes, total cost of delay is estimated as follows:

Total Cost of Delay= Change in Delay*Fuel Consumption rates*Unit Price of Fuel

\subsection{Data Collection and Collation}

Detailed data of Lahore-Sheikhupura-Faisalabad Dual Carriageway were collected from LAFCO. Traffic data for the period of 2008 to 2014 were obtained from LAFCO which provided number of vehicles passing through each toll plaza. In order to estimate future years traffic (20152028) a $4 \%$ annual traffic growth was considered, thus AADT was predicted for the life time of the facility. Also data on toll rates for entire concession period (2006-2028) and details of LAFCO M\&R strategy (including cost and timing of different treatments) were collected. The data on consumer price indices (CPI) were obtained from Pakistan Bureau of Statistics. CPI values for future years were estimated using extrapolation techniques.

\subsection{Economic Efficiency Analysis}

Each transportation investment decision is associated with a set of benefits and cost. Economic efficiency is used as a decision-making tool to select best alternative by incorporating all costs and benefits that are associated with an intervention. In present study net present value is used as performance criteria as it is a highly preferred technique used for project evaluation [7], [10], and [11]. Economic efficiency analysis is carried out using 22- years life cycle (analysis period) and duly incorporating all benefits (travel time saving, safety saving, fuel saving, toll collected) and operational and maintenance costs of the project. All costs are in 2007 constant \$US to arrest the inflation.

\section{Results and Analysis}

For detailed analysis the facility was divided into five segments based on toll plazas that are constructed on facility and allow only controlled access to facility. Travel time saving was calculated separately for each vehicle class depending upon its occupancy. A total of 33 minutes of travel time saving was obtained on entire facility $(3,8,5.5,9$ and 7.5 minutes on five different segments). The total travel time savings was estimated to be US\$ 429.29 Million (2007 Constant \$). For estimation of safety saving unit crash cost was estimated using per capita income of Pakistan for 2007 (\$1085). Following [12] fatal crash cost was estimated as \$US 75,950 (70 x times of per capita income) and non-fatal crash cost was estimated as \$US 19,530 (18 x times of per capita income). Since for first eight years actual data were available, therefore data on reported fatal and non-fatal crashes was used to find crash cost. In future year's traffic volume is expected to increase, and is likely to result in more crashes. Thus safety benefits of highway upgradation in initial years of intervention are expected to diminish. Thus net benefit of US\$ -1.79 Million (2007 Constant \$) was estimated. Using the 2007 fuel rates overall fuel cost savings was estimated to be US\$ 65.08 Million (2007 Constant \$). Major vehicles using this facility are cars, jeeps, wagons, buses, mini trucks, 2-axle trucks, multi axle trucks and trucks with trolleys carrying different agricultural and industrial goods. Toll rates have been agreed upon between concessioner (LAFCO) and client (Government of Punjab, Pakistan) and have been published in Government of Pakistan Schedule. As per agreement toll to be increased $5.74 \%$ annual (13). Since Operations and maintenance is the responsibility of concessioner (LAFCO), therefore toll collection is also the responsibility of concessioner (LAFCO), however concessioner (LAFCO) is bound to share details of collected toll with client (Government of Punjab, Pakistan. Total toll collection was estimated to be US\$ 131.41 Million (2007 Constant \$).

For estimation of Operational and maintenance cost data were collected from concessioner (LAFCO). As per concession agreement, concessioner is responsible for keeping the highway to a minimum desirable operational standards. In addition to initial construction (upgradation of facility from 2-lanes to 4-lanes divided highway) and carry out maintenance and rehabilitation as per schedule given in Figure 2. Using data from National Highway Authority (NHA) of Pakistan and LAFCO estimates, present worth of M\&R expenditures was estimated to be Operational expenditure Pakistan Rupee US\$ 227.830 Million (2007 Constant \$). Also operation expenditure that include toll collection and limited emergency response are estimated to be $5 \%$ of toll collection as US\$ 6.592 Million (2007 Constant $\$$ ). Overall facility upgradation benefits indicate that invested money has helped in improving travel time and saving in fuel cost.

BOT is a common public private partnership structure used around the globe [14]. BOT projects face inherent challenges and require support of the host government, good governance, transparent bidding, political stability and economic climate suitable for investment [15-18]. Pakistan is a developing country, therefore government support is vital for success of BOT projects is the country. 


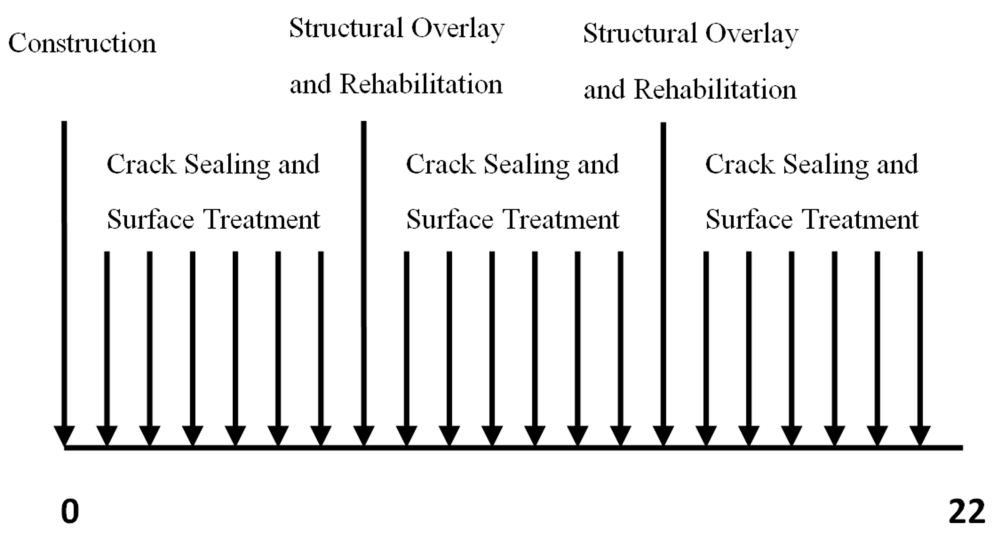

Figure 2. Maintenance and Rehabilitation Schedule as per Concession Agreement.

Summary of present worth of benfits and costs presented in Table 1

Table 1. Summary of Present Worth of Benefits and Cost.

\begin{tabular}{|c|c|c|c|}
\hline \multirow{2}{*}{ Details } & \multicolumn{2}{|c|}{2007 Constant US\$ (Million) } & \multirow{2}{*}{ Remarks } \\
\hline & Benefits & Costs & \\
\hline Travel Time Saving & 429.290 & - & \\
\hline Safety Saving & -1.790 & - & \\
\hline Fuel Saving & 65.080 & - & \\
\hline Toll collection & 131.410 & & \\
\hline Repair and Maintenance & - & 227.830 & \\
\hline Operations & - & 6.592 & \\
\hline Net Present Worth & & \$US 389.568 & \\
\hline
\end{tabular}

\section{Summary and Conclusions}

Present research effort used a realistic framework that incorporated the actual highway maintenance and rehabilitation practices used by concessioner and travel time, safety, fuel cost, lifecycle agency maintenance and operations cost, and lifecycle toll collection as performance measures to carry out post-implementation evaluation of Lahore-Sheikhupura-Faisalabad Dual Carriageway, a 4-lane divided highway that was constructed in 2006 through Build-Operate-Transfer (BOT) financing. Present worth (2007 constant US\$) of travel time, safety and fuel saving was found to be $429.290,-1.790, \quad 65.080$ Million US\$ respectively. Using facility operator's maintenance and rehabilitation strategy total maintenance and operations cost was found to be 234.442 Million ((2007 constant US\$). Also, present worth of toll collection was estimated as 131.410 Million (2007 constant US\$). Positive net present value revealed that project is economically viable for society [7], [12].

It was further revealed that BOT projects are economically viable and can be used by highway agencies in Pakistan for development of road infrastructure. Also, methodology used in present study can be used by highway agencies for carrying out post-construction evaluation of their projects. In order to ensure optimal utilization of public money, best project evaluation practices and monitoring of the expected impacts of highway investment decisions are recommended for highway agencies in Pakistan.

\section{Acknowledgements}

The contents of this paper reflect the views of the authors who are responsible for the contents and the accuracy of the data presented herein. Contents of this paper do not necessarily reflect the official views or policies of the Communication and Works Department of Governament of Punjab and Frontier Works Organization.

\section{References}

[1] Khan M. A., Ahmed, A, Kayani W. (2018). Optimal Timing for Lane (s) Addition to an Existing Highway: A Benefit-Cost Approach. Arab J Sci Eng (2018).

https://doi.org/10.1007/s13369-018-3350-8.

[2] Sinha, K. C. \& Labi, S. (2007). Transportation decision making: Principles of project evaluation and programming, John Wiley \& Sons.

[3] New Zealand Transport Agency (2014). Post Implementation Review Lake Road Widening. Available at https://www.nzta.govt.nz/assets/planning-and-investment/docs /post-implementation-reviews/2013-2014-pir-auckland-transp ort-lake-road-widening.pdf.

[4] Cambridge Systematics. (2000). A Guidebook for Performance- Based Transportation Planning, NCHRP Rep. 446, National Academy Press, Washington, DC.

[5] TRB (2000). Highway Capacity Manual, Transportation Research Board, National Research Council, Washington, DC.

[6] COMSIS Corporation, Scientific Applications International Corporation, Garman Associates (1995). Development of Diurnal Traffic Distribution and Daily, Peak, and Off-Peak Vehicle Speed Estimation Procedures for Air Quality Planning, Work Order B-94-06, Federal Highway Administration, U.S. Department of Transportation, Washington, DC.

[7] FHWA (1998). Highway Statistics, 1997. Office of Highway Information Management, Federal Highway Administration, Washington, DC.

[8] Bai Q., Ahmed A., Labi S Sinha KC (2017). Traffic Volume Benchmarks for Major Arterial Widening versus Expressway Construction: Exploratory Approach. Journal of Transportation Engineering, Part A: Systems, 2017, 143 (8). 
[9] AASHTO (2003). User Benefit Analysis for Highways, American Association of State Highway and Transportation Officials, Washington, DC.

[10] Diaz, C. E. D. "A Framework for Determining the Viability of Public-Private Partnerships for Toll Road Projects in the Philippines". Journal of the Eastern Asia Society for Transportation Studies, vol. 8, pp. 174-186, 2010.

[11] Azmi Mohamed et al. A Framework and Evaluation Technique for Project's Viability of Privatization Highway Projects in Malaysia. International Journal of Engineering and Technology Vol 9 No 6 Dec 2017.

[12] NSC (2001). "Estimating the Costs of unintentional Injuries". 2000 National Safety Council, Spring Lake Drive, Itasca, IL.

[13] Lahore and Faisalabad Construction Company (LAFCO) Private Limited (2005). Concession Agreement LAFCO.

[14] Kahyaogullari, B. (2013). Public-private partnerships in developing and developed countries: the UK and Turkish cases, Afyon Kocatepe Üniversitesi, IIBF Dergisi C. XV, S. II, 2013.

[15] Durdyev, Serdar \& Ismail, Syuhaida. (2017). The build-operate-transfer model as an infrastructure privatization strategy for Turkmenistan. Utilities Policy. 48. 195-200. 10.1016/j.jup.2016.12.002.

[16] Sharaffudin, H., Al-Mutairi, A., (2015). Success factors for the implementation of the build operate transfer (BOT) projects in Kuwait. Int. J. Bus. Manag. 10 (9), $68 \mathrm{e} 78$.

[17] Alinaitwe, H. and Ayesiga, R. (2013). 'Success Factors for the Implementation of Public Private Partnerships in the Construction Industry in Uganda', Journal of Construction in Developing Countries, 18 (2), 1-14.

[18] Ahmadabadi A. A., Heravi G. (2018). The effect of critical success factors on project success in Public-Private Partnership projects: A case study of highway projects in Iran, Transport Policy, 2018. https://doi.org/10.1016/j.tranpol.2018.07.004. 